\title{
RESIDENTIAL FIELD SITE TRAINING PROJECT ABSTRACTS
}

\author{
46 Batch, Session: 2003-04, $4^{\text {th }}$ year MBBS Students, CMC
}

\section{Study on health problems among geriatric population in rural community.}

Students : 28. Mohammad Riyadh, 29. Fahmida Hossain, 35. Md. Zakir Hasan, 39. Shusmita Saha, 44. Sayed Sharif Ahmmad Jilani, 45. Tahsina Afrin Sharmin, 47. Ansar Uddin Ahmed, 48. Sadia Jamir, 49. Abu Saleh Md. Ismail, 165D. Nahid Sultana.

Teacher Guide : Dr. Saroj Kumar Mazumder, Associate professor, Community Medicine Department, Chittagong Medical College, Chittagong.

\begin{abstract}
A descriptive study was conducted in May 2007 at Gopinathpur and Gabindapur villages of Mirsharai Upazilla under Chittagong district, $60 \mathrm{~km}$ away from Chittagong Medical College, with the intend to assess the disease pattern among geriatric population. A total of 147 elderly were enrolled in the study purposively. Among them $46.94 \%$ were male and $53.06 \%$ female. Majority $(46.94 \%)$ were young-old (60-64yrs) and only $11.56 \%$ were old-old ( $\geq 80 \mathrm{yrs}$ ). Major proportion (46.93\%) of the elderly was housewife by occupation followed by service holder $(25.17 \%)$. The $59.87 \%$ had spouse and $26.53 \%$ had self income. Major proportion (40.68\%) of elderly was suffering from cardiovascular diseases followed by musculoskeletal problems $(34.48 \%)$. The major diseases of male were hypertension $(36.76 \%)$, asthma $(30.88 \%)$, arthritis $(26.47 \%)$, diabetes $(17.65 \%)$ and hearing impairment $(13.25 \%)$. On the contrary in female it was hypertension $(44.16 \%)$, arthritis $(41.56 \%)$, asthma $(27.27 \%)$, cataract $(22.08 \%)$ \& gastritis. Hypertension (94.73\%) in CVD and asthma $(77.10 \%)$ in respiratory group were more prevalent disease irrespective of their tobacco habit in the form of smoking and betel-quid chewing. Most (73.91\%) male elderly were smoker. It was documented that $81.08 \%$ sought treatment from qualified doctor; $57.02 \%$ attended to MBBS doctor for the 1st time and $26.45 \%$ attended for second time. Most ( $\geq 90 \%$ ) elderly with education level of $\geq$ SSC, attended to MBBS doctor at the 1st time. Major proportion (59.30\%) of female was satisfied with their current status of living condition whereas majority $(55.74 \%)$ of male was unsatisfied.
\end{abstract}

2. Study on prevalence of diseases among under

\author{
children in a rural area of Mirsarai in the district \\ of Chittagong.
}

Student : 87. Md. Abdul Gaffar, 89. Kazi Newaz Rashed, 90. Abdullah Al- Mamun, 97. Efat Sharmin, 100. Ruhina Tasmin, 101. Nazmun Nahar, 103. Faria Sharmin.

Teacher Guide : Dr. Dewan Md. Harunur Rashid, Assistant Professor, Community Medicine Department, Chittagong Medical College, Chittagong.

\begin{abstract}
A descriptive cross sectional study was conducted with a view to study the prevalence of disease patterns among under 5 children of East Khaiachara, a village of Mirsarai upazilla, in the District of Chittagong in the month of June' 2007. A total of 105 children were selected by non-probability convenience sampling technique. The result revealed that majority $(37.14 \%)$ of the respondents was illiterate, followed by $26.67 \%$ to secondary level of schooling. Most $(69.52 \%)$ of the children belonged to lower socio-economic status (SES) family followed by lower middle SES (20.59\%). The $35.24 \%$ of fewer than 5 children were in the age group of 4-5 years. It was found that $64.76 \%$ of children were suffering from disease. The common diseases affected the children were ARI $(41.20 \%)$, skin diseases $(23.53 \%)$, diarrheal diseases $(16.18 \%)$, PEM (19.00\%) and other diseases (13.24\%). It was noted that most of cited diseases were predominant in children of illiterate mothers belonged in lower SES family. ARI was mostly ensued in children of lower SES (61.50\%) and lower middle SES (32.7\%). Diarrheal diseases were mainly occurred in rainy season $(40.00 \%) \&$ summer $(25.00 \%)$. On the contrary ARI occurred in winter $(57.00 \%)$ and rainy (21.3\%) season. Majority of children used sanitary latrines. The study revealed the disease scenario of the children was more or less consistent with the national picture.
\end{abstract}

3. Study on care seeking behavior of mother during pregnancy in a selected village of rural community.

Student : 120. Md. Resel, 124. Abeda Mohosina Nihat, 127. Jannatul Ferdous, 130.Mst.Shaila Afroz, 131. Sylveea Mannan, 137. Ehsanur Reza, 138. 
Konica Dey, 139. Tamanna Sultana, 140.Masuma Tabassum.

Teacher Guide : Dr. Tazkia Bashirullah, Lecturer, Community Medicine Department, Chittagong Medical College, Chittagong.

\section{Abstract}

This was a descriptive study conducted from May to July, 07 at west Khaiachara of Mirsarai under Chittagong district, to assess the care seeking behavior of mother during pregnancy. A total 152 women of reproductive age group were included purposively and interviewed with semi-structured questionnaire. Among the respondents $58.00 \%$ were in the age group of $\geq 22$ years and $60.00 \%$ of their husbands were in $\geq 35$ years of age. Majority of both husbands $(40.00 \%)$ and wives $(31.00 \%)$ were illiterate. Only $15.00 \%$ of women had completed SSC level of schooling. More than $99.00 \%$ of the respondents were housewives and their husband's were farmer $(27.00 \%)$ \& business $(24.00 \%)$ by occupation. Lower middle class gripped the highest proportion $(56.00 \%)$ of women followed by lower class $(26.00 \%)$. Women got married within the age $18-22$ years were $59.00 \%$ and about $68.00 \%$ became pregnant for the 1st time in the same age. Only $10.00 \%$ become pregnant after 22 years. Most (93.68\%) of women received ANC, among them $34.82 \%$ had paid 3 times with $50.00 \% 3 \& \geq 4$ times combined frequency of visits. The women $(18.50 \%)$ who did not attended for ANC, majority were illiterate $(51.85 \%)$ \& came from lower socioeconomic class of families. A large proportion (35.53\%) received ANC from Upazila Health Complex (UH-FWC) and private clinic (31.58\%). In over $60.00 \%$ cases physicians were the care provider. In most cases $(82.98 \%)$ women delivery was ensued at home. This was conducted by dai in $80.92 \%$ cases (TBA trained $=30.15 \%$ and $\mathrm{TBA}$ untrained $=67.46 \%$ ). $\geq 21.00 \%$ developed puerperal complication, mainly PPH ( $\geq 19.74 \%$ ). Apart from this was that irrespective of various educational level $52.63 \%$ had immunized with TT completely and $56.00 \%$ took additional food during pregnancy. About $38.00 \%$ women were reluctant to family planning method. Women taking oral contraceptive pill were $50.00 \%$ and the rest were adopting other methods.

4. A study on male participation in family planning in a rural Community of Mirsarai, Chittagong.
Students : 12. Md. Hossain Rahman, 15. Shusmita Sharmin, 16. Nahid Sultana, 17. Md. Omar Faruqe, 18. A.K.M.Moinul Hossain, 20. Gazi Md. Imran Hossain, 21. Md. Mosharaf Hossain Talukdar, 22. Saima Niamatullah, 13. Murshida Akter, 14. Md. Kamal Hossain.

Teacher Guide : Dr. Karimun Nahar, Lecturer, Community Medicine Department, Chittagong Medical College, Chittagong.

\section{Abstract}

This study was conducted among women of child bearing age in Moddhom Mogadia of Mirsarai under Chittagong district in July and August' 2007, to evaluate male participation in family planning activities. This was a descriptive study in which 102 women were selected purposively. More than $57.00 \%$ of respondents were in the age group of 21 30 years and about $60.00 \%$ from lower middle socio-economic class of families. Majority of both husbands $(32.00 \%)$ \& wives $(43.00 \%)$ were illiterate. By occupation $\geq 30.00 \%$ was cultivator. The $59.00 \%$ of couples dwelled in joint family. Main decision maker of family was the husband in $70 \%$ of cases and the rest by others. The study revealed that $75.5 \%$ of respondents were using FP methods currently. Considering the types, $46.00 \%$ used OCP, $45.00 \%$ injections, $5.00 \%$ permanently sterilized and the rest practiced other measures. Regarding selection of method; $42.00 \%$ by wives alone, $41.00 \%$ combined decision. Husbands played positive role in $16.50 \%$ cases. More than $89.00 \%$ husbands assisted their wives to collect FP methods, amid $\geq 61.00 \%$ accompanied their spouse to go to health centers for consultation and receiving treatment in case of complications. Among the couples $(\geq 24.00 \%)$ who did not practice FP methods, $72.00 \%$ were discouraged by their husbands and $28.00 \%$ due to lack interest or knowledge. About $64.00 \%$ of respondents were satisfied with 2 children and only $7.00 \%$ with 1 child. $\geq 24.00$ preferred 3 children. The respondents (6.86\%) who did not get expected results expressed their feelings about non-cooperation of husbands to make FP a successful one.

5. A survey on knowledge and practice of infant feeding among the lactating mothers in a selected Bangladeshi upazilla

Students : 51. Md. Mustafa Allama Talukder, 54. Muhammad Irfanul Alam, 56. Syed Mahbub Hossain, 58. Md. Jaynul Abedin, 67. Tahmina akter, 
72. Tahmina Dewan, 76. Sheikh Sadia Haque, 78. Mohammad Ullah, 84. Rumana Begum.

Teacher Guide : Dr. Fateha Akhter, Lecturer, Community Medicine Department, Chittagong Medical College, Chittagong.

\section{Abstract}

This study was carried out among 107 lactating mothers in Mirsarai upazilla of Chittagong, to assess the current knowledge and practice of infant feeding. The study documented that the age group 25-29 years gripped the majority $(28.97 \%)$ of the respondents. Among the mothers $39.25 \%$ were primary educated and $25.23 \%$ had completed secondary level of schooling. About $50.00 \%$ of the mother came from lower middle class of families with $87.80 \%$ were housewives by occupation. Most of the mother $(89.70 \%)$ knew about importance of breast feeding. $\geq 50.00 \%$ provided pre-lacteal food, among them mostly $(85.18 \%)$ used honey. More than half $(54 \%)$ of the mothers started weaning at 5 6 months. Mothers of lower middle socio-economic status (SES) and above started weaning in the appropriate time. On the contrary most $(61.5 \%)$ of the lower SES class started weaning at $\geq 7$ months. Regarding the types of weaning food, majority $(53.8 \%)$ of respondents of upper SES mothers used baby cereal and most (53.8\%) of lower SES uses rice powder. This study clearly stated the relationship between education level and knowledge about importance of breast feeding. Most of the secondary (55.6\%) and $\geq S S C(61.0 \%)$ level educated mothers started weaning in 5-6 months age of their babies. But most $(46.7 \%)$ of the illiterate mother started weaning in $\geq 7$ months. For heighten the awareness and practice of infant feeding among mothers it should be tailored to the economic development of the country.

6. A study on pattern of birth practice and the role of TBA in a selected village of Mirsarai upazila.

Students : 143. Mahmood Rahman, 144. Md. Monsur Ahmed Kayser, 145. Rifat Sharmin, 146. Kazi Bashir Ahmed, 147. Md. Mejbaul Khan, 148. Mohammad Arafatul Osmany,

Teacher Guide : Dr. Sayeed Mahmud, Lecturer, Community Medicine Department, Chittagong Medical College, Chittagong.

\section{Abstract}

This was a descriptive type of cross sectional study conducted in a selected village of East hinguli, Mirsarai, Chittagong, in May, 2007, to assess the pattern of birthing practice among the women of reproductive age. The study sampled 101 women purposively. The results revealed that majority (35.64\%) of respondents were in the age group of 25-29 years and over $96.00 \%$ were housewife by occupation. Most (61.39\%) of respondents had 1-2 children. Only $8.92 \%$ had 4 children. It was found that a large percentage $(58.42 \%)$ of mother were in primary level of education. Majority $(30.69 \%)$ were from lower middle class family. $\geq 86.00 \%$ mentioned about regular menstruation. $10.89 \%$ had history of irregular menstruation and dysmenorrhea $(2.97 \%)$. Approximately $85.00 \%$ mother attended with frequency of 1 or 2 times for ANC. More than $95.00 \%$ immunized with TT : $34.64 \%$ completely and $60.39 \%$ incompletely. $61.31 \%$ mothers received Vit-A and over $66.00 \%$ took extra supplementary food during pregnancy. Almost $91.00 \%$ of delivery was ensued at home. Only $4.95 \%$ performed caesarian section. Small percentages $(7.92 \%)$ choose govt. hospital for delivery. Most $(89.02 \%)$ of the delivery was attended by dai: $53.47 \%$ untrained TBA and $35.64 \%$ trained TBA. $82.00 \%$ pregnancy were full term and $14.00 \%$ were preterm. The weight of newborn in $79.10 \%$ cases were average and in $20.00 \%$ below average.

7. Epidemiological study on nutritional status of mother of reproductive age in a selected village of rural community.

Students : 201. .Md. Rezaul Haider Chowdhury 203. Md. Khairul Islam. 204. Sharmin Ayesha. 205. Kohinoor Begum. 206. Pranesh Chandra Pondit. 79.D. Md. Belfar Hossain. 80.D. Md. Alimur Rajib. 156.D. Hasan Md. Ashiqur Rahman. 194.D. Md. Tahir Ahmed Khan.

Teacher Guide : Dr Zahura Khanam, Lecturer, Community Medicine Department, Chittagong Medical College, Chittagong.

\section{Abstract}

This cross sectional study conducted with a view to assess the nutritional status of mother's of reproductive age in a rural community at west khaiar chara of Mirsarai upazilla under Chittagong district in June and June 2007. Majority (72.22\%) of the respondents were well-nourished (BMI: 18.5-25) with $17.36 \%$ undernourished (BMI: < 18.5), 9.03\% over weight (BMI: $>25-30$ ) and obese (BMI: $>30$ ). Majority of respondents in normal BMI, were in the 
age group of $20-29$ years $(65.38 \%)$ with their husbands age of $25-34$ years $(50.00 \%)$, housewives $(89.43 \%)$ with husband's occupation of service $(22.12 \%)$ \& small trader $(23.8 \%)$. They were educated up to primary $(32.69 \%)$ with husbands secondary level (35.58\%), belonged to lower middle class $(43.27 \%)$. Majority $(55.77 \%)$ of the family comprised of 4-6 members. Most (43.27\%) of the women had 2 children followed by one (31.73\%). On the contrary, who were malnourished (BMI: $<18.5)$ majority were also determined by same variables as normal BMI. Mother in family of $\geq 7$ members had never suffered from obesity.

8. A study on the socio-demographic characteristics and some selected health related behavior of rural Bangladeshi woman.

Students : 30. Bilash Kumar Saha, 31. Sarder Mohammad Giasuddin, 32. Nazmin Akhter Farzana, 34. Md. Mamunur Rashid Bhuiyan. 36. K.M. Rezwanul Isslam, 37. Sadia Sharmin, 40. Md. Daloarul Islam, 41. Amit Roy Chowdhury, 42. Didar Mahmud, 46. Farzana Azma Azad, 50.Tonmoy Biswas.

Teacher Guide : Dr. Saroj Kumar Mazumder, Associate professor, Community Medicine Department, Chittagong Medical College, Chittagong.

\begin{abstract}
This was a descriptive type of cross sectional study conducted in May and June, 2007 at Mirsarai upazila under Chittagong district. A total of 147 women who were at reproductive age having fewer than 5 years children were enrolled in the study. Data were collected by face to face interview using convenient sampling technique. The result revealed that the age group of less than 30 years griped the major proportion $(66.66 \%)$ of the respondents. The mean age was $25 \pm 3.4$ years. They were mostly (95.91\%) housewives by occupation and majority (29.93\%) had passed SSC level of schooling. Majority (37.41\%) dwelled in semi-pucca house. Most of the respondent had access to tube-well water $(100.00 \%)$ and sanitary facilities $(91.16 \%)$ irrespective of socio-economic status and educational level of their head of household. It was documented that most $(89.79 \%)$ of the women attended for ANC with $70.45 \%$ practiced it regularly. They received ANC mainly from govt. health facilities like Upazila health complex (47.72\%), Union health centre $(24.24 \%)$ and satellite clinic
\end{abstract}

$(6.81 \%)$. More than $79 \%$ of women received TT dose completely and over $74 \%$ received additional food during pregnancy. Home delivery for major proportion $(76.20 \%)$ of respondents and complete EPI-vaccination coverage $(91.11 \%)$ of their children were independent on the socio-economic class difference. Beside these, they sought treatment from qualified doctor for their common ailments in most cases $(67.74 \%)$. 